\title{
IDIOMS IN ACTION: A CASE OF CONCEPTUAL METAPHOR THEORY VS BLENDING THEORY
}

\author{
Yurii Kovalyuk \\ Chernivtsi National University \\ y.kovalyuk@chnu.edu.ua
}

This paper addresses the question of how the Conceptual Metaphor Theory with its well-established mechanism of cross-domain conceptual mappings, on the one hand, and the Conceptual Integration Theory, or Blending Theory with its mechanism of combining two or more input spaces into an emergent novel conceptual structure, on the other hand, can be rigorously applied to the cognitive linguistic analysis of idioms, such as damaged goods, for example. Subsequently, the studies done so far in this are examined and the two approaches are directly employed in the idiom analysis. The hypothesis as to whether Blending Theory, as opposed to the Conceptual Metaphor Theory, can be more productive in the idiom analysis in terms of input and output information involved is tested. It is argued that, if contrasted with the Conceptual Metaphor Theory, Blending Theory tentatively provides a more convincing and multifaceted toolkit for the idiom analysis. First, it is metaphorically-based. Second, it involves two or more input spaces for the conceptual structure representation, whereas there is only one cross-domain mapping mechanism put forth in the Conceptual Metaphor Theory. Third, it allows for context-dependent meaning construction. Fourth, it outlines the set of cognitive operations leading up to idiomatic creativity. The article findings affirm these assumptions yet also suggest that cognitive linguistic accounts of idioms will benefit from the combined application of the two approaches, as opposed to their standalone use.

Keywords: idioms; cognitive linguistics; Conceptual Metaphor Theory; Blending Theory; mental spaces; mapping.

\section{Introduction}

Cognitive linguistics has provided powerful tools for language study in terms of its experiential and cultural dimensions. When it comes to idioms and multi-word units in cognitive linguistics, one foregrounding theory seems to be clearly prevalent - Conceptual Metaphor Theory (Lakoff \& Johnson, 2003). Inspired by the idea that thoughts are deeply metaphoric or metonymic by nature, it has been posited that humans tend to map their concrete experiences onto abstract ideas. This tenet was convincingly substantiated in further monographs (Lakoff, 1987; Kövecses, 2015; Gibbs, 2017; Callies, 2017; Strack, 2019). Surprisingly enough, it was not only linguistic metaphors, but also formulaic language (Wood, 2015), most notably idioms, that provided the empirical evidence for the exemplification of conceptual metaphors. Put simply, idioms such as to take one's chances, an ace up one's sleeve, to hold all the aces, etc. are believed to conceptualise various facets of the LIFE IS A GAMBLING GAME metaphor theme. Though widely applied in a number of surveys on idioms and phraseology in general (Jaki, 2014; Colston, 2015; Omazic, 2015; Dabrowska, 2018), the Conceptual Metaphor Theory established what is referred to as the first wave of interest in figurative idioms (Boers, 2014). What is more important, in cognitive linguistics, idioms are still part of the far-reaching theories of Conceptual Metaphor (Callies, 2017) and figurative language (Sullivan, 2013; Dancygier and Sweetser, 2014; Colston, 2015; Liontas, 2015; Dobrovol'skij \& Piirainen, 2018). Lakoff and Johnson (2003: 52), for example, refer to them as "speech formulas", "fixedform expressions", "phrasal lexical items" and it is only in his later monograph that Lakoff (Lakoff, 1987, p. 448-453) himself refers to idioms proper, not providing a well-structured account of them.

On the contrary, more recent advances in Cognitive Linguistics have produced what is known as the Conceptual Integration Theory, or Conceptual Blending Theory (Fauconnier \& Turner, 2008; Brand, 2013; Turner, 2014; Booth, 2017; Bullo, 2017; Lowe et al., 2019). This framework, which is based on the Conceptual Metaphor Theory and the Mental Spaces Theory, holds that words, symbols, images, and concepts subject to cognitive operations are combined into a network of "mental spaces" for meaning creation. A conceptual integration network often involves two input spaces related by a generic space and, hence, a blended space. The network model, by mere definition, is concerned with "on-line, dynamic cognitive work people do to construct meaning for local purposes of thought and action" (Fauconnier \& Turner, 2008, p. 368). Blending, therefore, is considered central to the way people think. The division of blends into simplex, mirror, single-scope, and double scope networks helps account for the ways in which input spaces can be combined in the blend. One convincing advantage of Blending Theory is its ability to provide compressions to the human scale of diffuse arrays of events (Fauconnier, 2018).

The purpose of this paper is to test the productivity of the Conceptual Metaphor Theory and the Blending Theory in the cognitive analysis of idioms. The objectives to be accomplished in this paper are as follows: to provide a theoretical account of idioms within the Conceptual Metaphor Theory; to describe 
select English idioms, both in their canonical and creatively modified representations, in terms of the Conceptual Metaphor Theory and the Blending Theory; to elucidate the strengths and weaknesses of each theory evidenced by the (contexts of) idioms under study; to outline the prospects for further research into idioms involving the Conceptual Metaphor Theory and the Blending Theory.

\section{Data and Methodology}

The data for the analysis, as part of a large corpus of English idioms comprising around 2,500 units, were taken from the Collins Cobuild Idioms Dictionary and the Corpus of Contemporary American English (COCA).

The methodology employed in the study is the Conceptual Metaphor Theory (Lakoff \& Johnson, 2003), on the one hand, which allows us to understand one domain of experience in terms of another (Lakoff \& Johnson, 2003, p. 117). As Kövecses (2015) puts it, "the domain of experience that is used to comprehend another domain is typically more physical, more directly experienced, and better known than the domain we wish to comprehend, which is typically more abstract, less directly experienced, and less known" (p. 2). On the other hand, Fauconnier's Blending Theory (Fauconnier 2008, 2018), which holds that "meaning construction involves the integration of structure that gives rise to more than the sum of its parts" (cited by Evans, 2007, p. 12), serves as a further methodological framework.

Guyla (2010) asserts that blends are manifest in all parts of the language given they operate at all levels of cognition from simplex networks to double scope integration (p. 240). According to Fauconnier \& Turner (2007), "mental spaces are small conceptual packets constructed as we think and talk, for purposes of local understanding and action" (p. 363). Oakley \& Pascual (2017) describe mental spaces as "dynamic, imagery-rich, real-time mental simulations" thus facilitating representation of objects, forms, events, and states. As regards idioms, Omazic (p. 54), for example, claims that blending is not only a meaning construction process but also an 'unpacking mechanism' for interpreting idiom modifications.

The following methods were applied: conceptual analysis for breaking down and analysing concepts underlying the idioms under study; context-situational method for interpretation of the contexts of idioms under study.

\section{Results and Discussion}

Let us start the discussion with the account of idioms within the Conceptual Metaphor Theory evidenced from the LIFE IS A GAMBLING GAME metaphor. Lakoff and Johnson (2003) substantiate the existence of the above conceptual metaphor with the following examples:

\section{LIFE IS A GAMBLING GAME}

I'll take my chances. The odds are against me. I've got an ace up my sleeve. He's holding all the aces. It's a toss-up. If you play your cards right, you can do it. He won big. He's a real loser. Where is he when the chips are down? That's my ace in the hole. He's bluffing. The president is playing it close to his vest. Let's up the ante. Maybe we need to sweeten the pot. I think we should stand pat. That's the luck of the draw. Those are high stakes. (Lakoff \& Johnson, 2003, p. 51)

What Lakoff and Johnson (2003) suggest is that the above "speech formulas," or "fixed-form expressions," or "phrasal lexical items" are invoked by a symbolic cognitive structure: a conceptual metaphor. The LIFE IS A GAMBLING GAME conceptual metaphor comprises a number of fixed crossdomain mappings.

Essentially, these mappings arrange ideas inherent of the more abstract domain of LIFE through concepts pertaining to the more concrete domain of GAMBLING GAME. In a point of fact, quite a number of concepts reside within the domain of LIFE. These encompass the experiential concepts of taking a risk or chances, having an advantage, maintaining a favourable position, even chances, displaying the right behaviour, being in a difficult or dangerous situation, keeping a hidden advantage or resource in reserve, raising the risk of an activity, increasing the stakes of something, and opposing change. In addition, the concepts for gambling and gamblers and their derivatives - risk-takers, winners, losers, equal opportunities, evidently inhere in the domain of LIFE, too.

In a similar vein, Lakoff and Johnson (2003) argue that gambles represent actions in life. These are betting, playing an ace (a card with the highest or lowest value), holding all high cards in a game, playing the right combination of cards in a game, making bets in poker, playing a hole-card in stud poker, keeping cards secret in a game, raising stakes in poker, and making bets by throwing new chips in. What the conceptual metaphor LIFE IS A GAMBLING GAME demonstrates is a set of mappings from the domain of GAMBLING GAME onto equivalent ideas in the domain of LIFE. In other words, ideas in the domain of 
LIFE are arranged in terms of information from the domain of GAMBLING GAME. To exemplify, winners and losers in the LIFE domain are interpreted in terms of card (poker) players to the extent that winners and losers in life are conventionally understood in terms of card (poker) players. Furthermore, a favourable position in life is conceived in terms of a beneficial set of cards to play with. Thus, the experience-derived LIFE IS A GAMBLING GAME conceptual metaphor presupposes that people experience actions in life as gambles where one takes one's chances, has an ace up one's sleeve or holds all the aces under toss-up and against-the-odds situations.

Further, but for the knowledge that is entrenched by the conceptual metaphor and stored in our memory, one would find it difficult to figure out the following idiomatic expressions in English: to perceive life situations as games of poker and people as poker players, etc. As mentioned before, it is the idiomatic expressions that provide the linguistic proof for the existence of the conceptual metaphor.

In Table 1, we have outlined the mappings that structure the LIFE IS A GAMBLING GAME conceptual metaphor. The arrow in Table 1 indicates the corresponding mapping between two concepts. For instance, the concept for playing cards is mapped onto the concept for displaying behaviour.

\section{Table 1. Mappings of the LIFE IS A GAMBLING GAME}

\begin{tabular}{|l|c|l|}
\hline Source domain: GAMBLING GAME & Mapping & Target domain: LIFE \\
\hline Gambler & $\rightarrow$ & Person \\
\hline Chances & $\rightarrow$ & Opportunities \\
\hline Odds & $\rightarrow$ & Circumstances \\
\hline Ace & $\rightarrow$ & Advantage \\
\hline Aces & $\rightarrow$ & Favourable position \\
\hline Toss-up & $\rightarrow$ & Even chances \\
\hline Play cards & $\rightarrow$ & Display behaviour \\
\hline Chips & $\rightarrow$ & Situations \\
\hline Stake & $\rightarrow$ & Risk \\
\hline Pot & $\rightarrow$ & Situation \\
\hline
\end{tabular}

Turning to the issue of the differences between the Conceptual Metaphor Theory and the Blending Theory, the following idioms will be analysed:

(1) damaged goods;

(2) Pandora's box;

(3) Trojan horse.

Consider a script excerpt from CBS THE EARLY SHOW for September 28, 2010, CBS retrieved from COCA, providing the context leading up to the idiom damaged goods, which could be paraphrased as 'a person who is regarded as inadequate or impaired in some way' (Collins Cobuild Idioms Dictionary):

Shortly after leaving, Lohan tweeted her fans about the experience. "What a great place The Dream Center is here in L.A. had a nice time there today, it's so important to give back. I feel blessed. "

KEN-BAKER: Lindsay has gone from being in jail to being out of jail to suddenly being sort of a Mother Teresa-like figure in nothing but a span of three days.

TARA-MERGENER: Some in Hollywood question the motive behind her sudden acts of kindness.

KEN-BAKER: It's no secret in Hollywood that Lindsay Lohan is damaged goods. The question is, can she repair herself and repair her image so that people will feel confident enough to hire her?

TARA-MERGENER: She's still signed on to play porn star, Linda Lovelace in Inferno.

CHRIS-HANLEY-1Pro: And she's the best actress for the part and, you know, we are still totally behind her and want her to be the lead.

TARA-MERGENER: Though the role Lohan most likely wants is that of a free woman. Tara Mergener, for CBS News [COCA].

Examined from the perspective of the Conceptual Metaphor Theory, the idiom damaged goods implies the specific metaphor REPUTATION IS GOODS. So as to be applicable to Lindsay Lohan, an American actress, the generic metaphor GOODS IS A PERSON has to be actuated as well, whose source concept PERSON comes with a notion of person's impaired public image. Hence, the metaphor REPUTATION IS GOODS is understood within the mapping scope grounded in the basic experience of what is good (or profitable) in terms of economics (selling damaged goods, i.e. those reduced in quality or performance, is unprofitable activity). 
In the case of Blending Theory, the context leading up to the idiom damaged goods is of crucial importance in its cognitive processing. One may assume that upon reading the first sentence and the preceding context of the sample text, the reader will elaborate a mental space containing the information that Lindsay Lohan has undergone a programme in a drug rehabilitation centre (The Dream Center is Pentecostal Christian Church mission which offers drug and alcohol rehabilitation programmes, among others). We will call this mental space "drug abuse space". This mental space is ad hoc construction incorporating such cognitive models as LINDSAY LOHAN, HOLLYWOOD ACTRESS, and DRUG AND ALCOHOL ABUSE. In addition to the "drug abuse space", the above idiom operationalises a second mental space, which will be referred to as "reputation damage space". This space generates a conceptual structure of an economically-derived cognitive model, which plays up a good (or goods) reduced in quality or performance due to bad shipping. Another implication arising from this cognitive model is that trading damaged goods results in reduced profits. What the Blending Theory postulates is that the two mental spaces above, which can otherwise be called input spaces, are merged together, or blend. The outcome of this cognitive activity is a new blended space containing the information from the two input spaces. Along with this information, the blended space contains an emergent structure, which is somewhat different from the input spaces. Fauconnier and Turner (2003, p. 48) claim that for the projection of the input spaces into the blended one three processes are necessary: composition, completion and elaboration. As far as composition is concerned, it operates when the conceptual content from input mental spaces is combined in the blended space, for example, damaged goods is construed as a person inadequate or impaired in some way. Completion as a process is indispensable for conceiving the blend given that the sentence It's no secret in Hollywood that Lindsay Lohan is damaged goods does not fully shed light on the situation. The preceding context helps the reader acquire information as to why Lindsay Lohan is likened to damaged goods, i.e. because she has received treatment for drug addiction. In the case of the elaboration process, Fauconnier and Turner (2003, p. 48) maintain that the blend can be enriched by information deemed necessary, pertinent or even just interesting. Thus, although the blended space describes Lindsay Lohan as a person with a tarnished reputation, who may experience difficulties finding employment in light of her alcohol and drug addiction, and who has to go to great lengths to repair her image, she still can count on the support of some film producers, like Chris Hanley.

Now let us ruminate over a statement courtesy of Ernest Bevin, the Labour Party Foreign Secretary in 1948, who commented on the idea of establishing a Council of Europe as follows:

"I don't like it. When you open that Pandora's box, you will find it full of Trojan horses. (Brandreth, 2015).

If approached from the Conceptual Metaphor Theory standpoint and not taking account of the context, the following interpretation of the above idioms may be suggested. First, the source concept of a horse in the Trojan horse idiom may be linked to a huge hollow wooden statue of a horse, which was used by the Greek soldiers in an attempt to enter and capture the city of Troy. The shared knowledge helps activate the further source concepts of the TROJAN WAR, the TROJAN WALL, and the GREEK ARMY, respectively. The source domain elements that can be mapped onto the target domain include several Trojan horses or entities intended to undermine an enemy or bring about their downfall. The other idiom, i.e. the Pandora's box, which appears superordinate to the Trojan horses' idiom, may invoke an episode from Greek mythology. The source concepts emanating from the myth comprise Pandora, the first mortal woman, Zeus the creator, a box of evils sent to the earth in an act of revenge against Prometheus, etc. The projection of the source concepts onto the target domain yields a process that once begun generates many complicated problems, parallel to what Pandora did, i.e. let out all the evils of the container to infect the earth. Thus, in line with the Conceptual Metaphor Theory, Pandora is identified as a revenger, Pandora's box is regarded as a container (of evils), and the act of opening symbolises the generation of problems. It follows that on the basis of the context provided the Trojan horses idiom reflects the ARGUMENT IS WAR conceptual metaphor. In the case of Pandora's box, it apparently instantiates the generic metaphor POLITICAL ORGANISATIONS ARE CONTAINERS, where the source concept is represented by a prospective political organisation, i.e. The Council of Europe.

In contrast, the target domain is conceived as countries affiliated with this organisation. Idiomatically speaking, and to be applicable to the political situation of 1948, the yet to be established Council of Europe (it was founded in 1949) is viewed as a Pandora's box, which can be evidenced by THE COUNCIL OF EUROPE IS PANDORA'S BOX metaphor. In other words, Pandora's box, in that case, stands for a political process which involves a number of complexities related to the Council of Europe establishment (as considered by the British Labour Party Foreign Secretary). The complexities further manifest themselves as Trojan horses, thus instantiating, first, a generic metaphor (EUROPEAN) COUNTRIES ARE DESTRUCTIVE AGENTS, and, second, a more specific metaphor (EUROPEAN) COUNTRIES ARE 
TROJAN HORSES. Such interplay of metaphors, in which one superordinate metaphor THE COUNCIL OF EUROPE IS PANDORA'S BOX subsumes the subordinate metaphor (EUROPEAN) COUNTRIES ARE TROJAN HORSES, can be referred to as mixed metaphors.

As far as the Blending Theory is concerned, say, the reader, upon coming across such a sentence, will apparently construct a mental space containing, quite obviously, the fact that countries of Europe intend to found a new political organisation. Let us refer to this mental space as a "political space". It follows that such a mental space is an online concept generated by virtue of incoming information but drawing out embedded cognitive models, such as the United Kingdom, European countries, international organisations, and, most importantly, The Council of Europe. Combined with the political space, the incoming idiomatic expression activates a second mental space, which will be referred to as "problem-inducing space". This space invokes the conceptual structure of a well-known cognitive model prototypically calling up an artefact originating from Greek mythology which contained all the evils of the world. Included is also the information about the nature of such an act, which is a process once begun generates many complicated problems. Yet, one point not to be overlooked is that, apart from the two mental spaces mentioned, one more mental space is hereby activated at the expense of the Trojan horse idiom. We shall call it "corrupt members space". Adjusted to this context, it triggers the knowledge of yet another infamous Greek mythology artefact - the Trojan horse, along with the consequences of such event, i.e. instability and uncertainty of the would-be political organisation. With this in mind, it is apparently three input spaces, not two, that make up this particular conceptual integration structure. The result of such conceptual integration arising from further conceptual blending and re-blending, as Evans (2007, p. 132) suggests it, is a mega-blend. A mega-blend is a conceptual integration structure featuring more than two input spaces. As regards this very context, the mix of the idioms opens Pandora's box and Trojan horse draws on three input spaces - "the political space", "the problem-inducing space", and "the corrupt members space". These relate to a situation, an entity and agents, accordingly. With this in mind, the situation is a political one taking place in the post-war Europe (in 1948) leading to the creation of the Council of Europe (in 1949). The entity in question is the Council of Europe, an international organisation aimed at promoting democracy, rule of law, human rights, economic development and integration in Europe. The agents are the European countries, i.e. prospective members of the Council of Europe. In the Pandora's box and Trojan horse blend, the first input space is political, because the position was expressed by the British Labour Party Foreign Secretary. The second input space is problem-inducing on the grounds that Labour Party Foreign Secretary, on behalf of Great Britain, is sceptical about the expediency and, hence, the viability of the yet to be established the Council of Europe. Last but not least, the third input space is posited as a "the corrupt members space", since some of the soon-to-be members of the Council of Europe are viewed as foes, not allies, by Ernest Bevin. In the final analysis, emergent is a novel cognitive structure, where the Council of Europe is conceived as a potentially problematic international enterprise with serious perils coming from its future associates.

\section{Conclusions}

To summarise our findings in the course of a fine and fascinating journey into the realm of English idioms, we would like to emphasise the following points of discussion. First, the Conceptual Metaphor Theory provides a fairly straightforward procedure of mapping our experiential domains in terms of another. For example, physically damaged from the economic vantage point may be perceived as mentally deficient in a figurative sense. To this end, extracts featuring idioms such as damaged goods, Pandora's box, and Trojan horse were scrutinised. As evidenced from the discussion above and in affirmation of the hypothesis put forth herein, Blending Theory does provide a more convincing and multifaceted toolkit for the idiom analysis if contrasted with the Conceptual Metaphor Theory. First, it is metaphorically based, i.e. drawing on the Conceptual Metaphor Theory. Second, it involves two or more input spaces for the conceptual structure representation, whereas there is only one cross-domain mapping mechanism suggested in the Conceptual Metaphor Theory. Third, it does rely on context, whilst context is not of major importance in the Conceptual Metaphor Theory. Fourth, it has proved indispensable in analysing on-line idiomatic creativity, as evidenced from the Pandora's box and Trojan horses mega-blend, thus corroborating the claims made by Omazic (2015) and Dzanic \& Dzanic (2009). However, we share the opinion of Barczewska (2017) that one shortcoming of Blending Theory is that it may fail to account for the multiplicity of implied meanings emerging from the blend based on discourse context, speaker/hearer culture, etc. Therefore, in our view, in order to avoid or to minimise, so to speak, potential pitfalls, it is best to employ the Conceptual Metaphor Theory and Blending Theory in tandem in the cognitive analysis of idioms.

Researching idioms within cognitive linguistic approaches opens up avenues for further interdisciplinary and integrative studies of language, providing insights on how figurative language units mean. The relatively understudied area, where figurative language can be investigated through the lens of the 
Conceptual Metaphor Theory and the Blending Theory, is professional communication, namely courtroom interactions, business meetings, and digital media discourse, to name a few.

\section{References:}

Barczewska, S. (2017). Applications of conceptual blending: Headlines and their implicatures. Jezikoslovlje, 18(3), $423-446$. Retrieved September, 2018 from https://hrcak.srce.hr/190907

Boers, F. (2014). Idioms and Phraseology. In Taylor, J., \& Littlemore, J. (Eds.), The Bloomsbury Companion to Cognitive Linguistics (pp. 185-202). New York: Bloomsbury Academic.

Booth, M. (2017). Shakespeare and Conceptual Blending: Cognition, Creativity, Criticism. London: Palgrave Macmillan. https://doi.org/10.1007/978-3-319-62187-6

Brand, L. (2013). The Communicative Mind: A Linguistic Exploration of Conceptual Integration and Meaning Construction. Newcastle upon Tyne: Cambridge Scholars Publishing.

Brandreth, G. (2015). Word Play: A Cornucopia of Puns, Anagrams and Other Contortions and Curiosities of the English Language. London: Coronet.

Bullo, S. (2017). Investigating intertextuality and interdiscursivity in evaluation: the case of conceptual blending. Language and Cognition, 9 (4), 709 - 727. https://doi.org/10.1017/langcog.2017.5

Callies, M. (2017). 'Idioms in the making' and variation in conceptual metaphor. Cognitive Linguistic Studies, 4(1), 63-81. https://doi.org/10.1075/cogls.4.1.04cal

Collins Cobuild Idioms Dictionary. (2012). London: Collins Cobuild.

Colston, H. (2015). Using Figurative Language. New York: Cambridge University Press. https://doi.org/10.1017/CBO9781316226414

Dąbrowska, A. (2018). A Syntactic Study of Idioms: Psychological States in English and Their Constraints. Cambridge: Cambridge Scholars Publishing.

Dancygier, B. \& Sweetser, E. (2014). Figurative Language (Cambridge Textbooks in Linguistics). Cambridge: Cambridge University Press.

Dobrovol'skij, D. \& Piirainen, E. (2018). Conventional Figurative Language Theory and idiom motivation. Yearbook of Phraseology. 9 (1), 5-30. https://doi.org/10.1515/phras-2018-0003

Dzanic, N. \& Dzanic, M. (2009). Idiom Modifications in Light of Conceptual Integration Theory. In Brdar, M., Omazić, M. \& Takač, V. (Eds.). Cognitive Approaches to English: Fundamental, Methodological, Interdisciplinary and Applied Aspects (pp. 201-225). Newcastle upon Tyne: Cambridge Scholars Publishing.

Evans, V. (2007). A Glossary of Cognitive Linguistics. Edinburgh: Edinburgh University Press.

Fauconnier, G. \& Turner, M. (2008). The Way We Think: Conceptual Blending and the Mind's Hidden Complexities. New York: Basic Books.

Fauconnier, G. (2018). Ten Lectures on Cognitive Construction of Meaning. Leiden: Brill Publishers. https://doi.org/10.1163/9789004360716

Gibbs, R. (2017). Metaphor Wars: Conceptual Metaphors in Human Life. New York: Cambridge University Press. https://doi.org/10.1017/9781107762350

Guyla, D. (2010). Culture, Language and Idiomaticity. Acta Universitatis Sapientiae, Philologica, 2(2), $237-245$. https://www.acta.sapientia.ro > acta-philo > philo22-3. Retrieved in September 2018.

Jaki, S. (2014). Phraseological Substitutions in Newspaper Headlines: "More Than Meats the Eye". Amsterdam \& Philadelphia: John Benjamins. https://doi.org/10.1075/hcp.46

Kövecses, Z. (2015). Where Metaphors Come From. Reconsidering Context in Metaphor. Oxford: Oxford University Press. https://doi.org/10.1093/acprof:oso/9780190224868.003.0002

Lakoff, G. \& Johnson, M. (2003). Metaphors We Live by. Chicago: The University of Chicago Press. https://10.7208/chicago/9780226470993.001.0001

Lakoff, G. (1987). Women, Fire, and Dangerous Things. What Categories Reveal about the Mind. Chicago and London: The University of Chicago Press.

Liontas, J. (2015). Straight from the Horse's Mouth: Idiomaticity Revisited. In Heredia, R. \& Cieślicka, A. (Eds.). Bilingual Figurative Language Processing (pp. 301-340). New York: Cambridge University Press. https://doi.org/10.1017/CBO9781139342100.016

Lowe, S., Kainzbauer, A. \& Ngamcharoenmongkol, P. (2019). Conceptual blending of meanings in business marketing relationships. Journal of Business \& Industrial Marketing, 34 (7), 1547 - 1554. https://10.1108/JBIM-10-2017-0247

Oakley, T., \& Pascual, E. (2017). Conceptual Blending Theory. In Dancygier B. (Ed.), The Cambridge Handbook of Cognitive Linguistics (pp. 423-448). Cambridge: Cambridge University Press. https://doi.org/10.1017/9781316339732.027

Omazic, M. (2015). Phraseology through the looking glass. Osijek: Josip Juraj Strossmayer University.

Strack, D. (2019). Metaphor from the Ground Up: Understanding Figurative Language in Context. Lanham, MD: Lexington Books.

Sullivan, K. (2013). Frames and Constructions in Metaphoric Language. Amsterdam \& Philadelphia: John Benjamins. https://doi.org/10.1075/cal.14

The Corpus of Contemporary American English. (n.d.). Retrieved 2018 from https://corpus.byu.edu/coca/

Turner, M. (2014). The Origin of Ideas: Blending, Creativity, and the Human Spark. New York: Oxford University Press.

Ungerer, F. \& Schmid, H.-J. (2006). An Introduction to Cognitive Linguistics. Harlow, England: Pearson Longman. https://doi.org/10.4324/9781315835396

Wood, D. (2015). Fundamentals of Formulaic Language. London: Bloomsbury Academic. https://doi.org/10.5040/9781474218771.ch-006 